\title{
The Influence of Online Learning on Academic Performance and Students' Satisfaction
}

\author{
Assoc. Prof. Dr. Nazmi Xhomara1, Dr. Mirela Karabina ${ }^{2}$ \\ ${ }^{1}$ Lecturer, Department of Mathematics and Statistics, Faculty of Information Technology and \\ Innovation, Luarasi University, Tirana, Albania. \\ ${ }^{2}$ Lecturer, Department of Social Sciences, Faculty of Social Sciences, Albanian University, Tirana, \\ Albania
}

\begin{abstract}
The study aims to examine the implementation of an online learning approach to improving academic performance and students' satisfaction. Analysis of Variance (ANOVA) was used to test the impact of online learning on academic performance and students' satisfaction. The study found that the variance of online learning is different, revealing that different levels of online learning influence academic performance. It is also found that approximately $49.7 \%$ of the variance in academic performance can be explained or accounted for by online learning differences. It is confirmed that the variance of online learning is different, revealing that different levels of online learning influence students' satisfaction. The study also found that approximately $78 \%$ of the variance in students' satisfaction can be explained or accounted for by online learning differences.
\end{abstract}

Keywords: online learning, academic performance, students' satisfaction 